DOI: http://dx.doi.org/10.21123/bsj.2016.13.1.0097

\title{
Addition of Some Primary and Secondary Amines to Graphene Oxide, and Studying Their Effect on Increasing its Electrical Properties
}

\author{
Ahmed Najem Abd Abdulwahhabb H.Al-Agha \\ Mustafa.A.Alheety
}

Department of Chemistry, College of Science, University of Diyala.

Received 22, October, 2015

Accepted 10, January, 2015

EY NC ND This work is licensed under a Creative Commons Attribution-NonCommercialNoDerivatives 4.0 International Licens

Abstract:

Previously many properties of graphene oxide in the field of medicine, biological environment and in the field of energy have been studied. This diversity in properties is due to the possibility of modification on the composition of this Nano compound, where the Graphene oxide is capable of more modification via addition other functional groups on its surface or at the edges of the sheet. The reason for this modification possibility is that the Sp3 hybridization (tetrahedral structure) of the carbon atoms in graphene oxide, and it contains many oxygenic functional groups that are able to reac with other groups. In this research the effect of addition of some amine compounds on electrical properties of graphene oxide has been studied by the preparation of graphene oxide - amino containing compound, which could be classified under Nano carbon compounds containing nitrogen (N-doped carbon nanomaterials). These amines are used as expanders for the distance between the layers of graphene oxide (spacers), and thus prevent agglomeration of graphene oxide layers in addition to enhanced electric properties of graphene oxide.

The following amines (thiocarbohydrazide $(\mathrm{TCH})$,o-phenylenediamine(oPD) and poly aniline(PAni)) were used for the preparation of the corresponding amino graphene oxide (GO-TCH, GO-containing Benzoimidazol \& benzoxazole, and GO-PAni), and characterized by X-RAY diffraction (XRD), infra red spectrum (FTIR) and atomic force microscope (AFM), also the electrical properties of these materials were studied using inductance, capacitance, and resistance ( LCR) measurements.

Key words: Electrical Properties, Primary and Secondary Amines, Graphene Oxide.

\section{Introduction:}

The deficiency in the quantity of fossil fuel and increasing of pollution that is considered as a main problem of nowadays, as result many researchers rush up to a find superior materials in order to use them in renewable energy devices to promote their performance. Graphene oxide is one of the carbon allotropes with a
Nano size that gives a high surface area and the ample of oxygenic functional groups that gives the ability to react and join with active or catalysis material [1]. This modification on graphene oxide makes it able to save and generate energy; furthermore, these functional groups give it porous structure, so it could be used as current collector or doped 
material for electrodes in supercapacitor or lithium batteries [2]. This distinctive nano structure of graphene oxide enables us to use it in various applications like electronics, fuel cells, supercapacitor and sensors. In principle, we can't use graphene oxide in applications that require electric conductivity. This is due to poverty of graphene oxide to electrical conductivity [3].

In this research, the addition of amines on graphene oxide surface has been studied for increasing the property that graphene oxide lacks and to obtain a higher conductivity material that can improve the used renewable energy device properties. Graphene oxide has many vital features like high surface area, disperse in water and produce a homogenous colloidal suspension, prepared by a simple and low cost method [4], not toxic, good mechanical properties and the most important point is that GO has many different functional groups. According to LerfKlinowski and Dékány Models [5, 6], the appropriate structure that contain: epoxy (bridging oxygen atoms) and hydroxyl in the basal plane and carboxyl and carbonyl moieties lining the nanosheet edges (Figure 1) and a small number of intercalated water molecules (5-15 wt \%) [7].

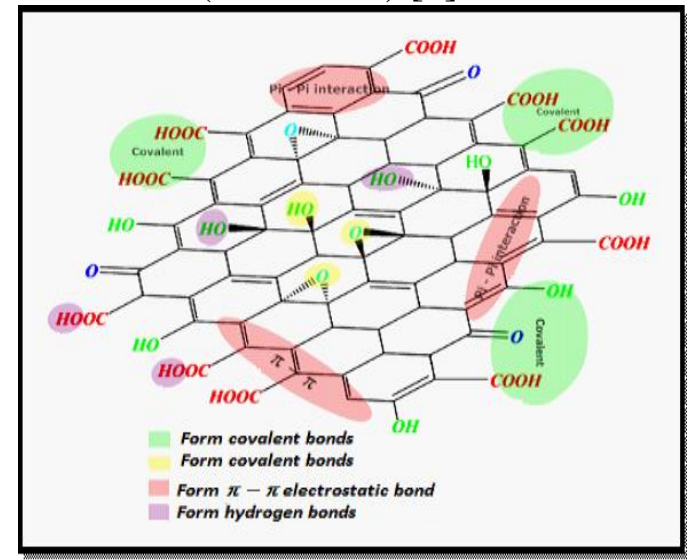

Fig.( 1 ) graphene oxide sheet and its active sites [8].

We have used different primary and secondary amines as functional groups added directly onto GO. These amines are bonded either covalently (with $\mathrm{COOH}, \mathrm{OH},-\mathrm{O}-$ ) or non-covalently (with Pi-Pi stacking, hydrogen bonding), (Figure 1), non covalent bond also called electrostatic bond [9]. The resulted materials have applications in optoelectronics [10 -12], catalysis [13], bio devices [14, 15], drug-delivery vehicles [16], supercapacitors [16], and polymer composites [17,18].

\section{Materials and Methods:-}

All chemicals including graphite powder, sulfuric acid $\left(\mathrm{H}_{2} \mathrm{SO}_{4}\right)$, sodium nitrate $\left(\mathrm{NaNO}_{3}\right)$, hydrogen chloride $(\mathrm{HCl}), \quad$ potassium permanganate $\left(\mathrm{KMnO}_{4}\right)$, hydrogen peroxide $\left(\mathrm{H}_{2} \mathrm{O}_{2}\right)$, hydrazine monohydrate $\left(\mathrm{N}_{2} \mathrm{H}_{4} \cdot \mathrm{H}_{2} \mathrm{O}\right)$, aniline $\left(\mathrm{C}_{6} \mathrm{H}_{7} \mathrm{~N}\right) \quad$ andoPhenylenediamine $\left(\mathrm{C}_{6} \mathrm{H}_{8} \mathrm{~N}_{2}\right)$ were of analytical grade and used as received without further purification except aniline.

\section{Preparation of materials: Preparation of GO:}

Graphene oxide prepared according to Hummers' method [19]. $50 \mathrm{ml}$ of concentrated $\mathrm{H}_{2} \mathrm{SO}_{4}$ was cooled down below $0{ }^{\circ} \mathrm{C}$ in ice bath for 30 minutes, $1 \mathrm{~g}$ of graphite was then added to cool concentrated $\mathrm{H}_{2} \mathrm{SO}_{4}$ and kept on constant stirring in an ice bath for 15 minutes. $4 \mathrm{~g}$ of sodium nitrate was added gradually. While maintaining vigorous agitation, $6 \mathrm{~g}$ of potassium permanganate were added to the suspension. The rate of addition was controlled carefully to prevent the temperature of the mixture from exceeding $10^{\circ} \mathrm{C}$. After 40 minutes, the color of the mixture changed from black to green due to the presence of oxidizing agent $\left(\mathrm{Mn}_{2} \mathrm{O}_{7}\right)$. The mixture was stirring for 12 hours in an ice bath. The ice-bath was then removed and the temperature of the mixture was kept at $35^{\circ} \mathrm{C}$ in water path for 20 hours. After that, the mixture became pasty(deep 
red- brown in color), then $50 \mathrm{ml}$ of DI water was then added to above mixture carefully and very slowly with vigorously stirring for 1 hour. The temperature reached $90-98{ }^{\circ} \mathrm{C}$ and avoided reaching more than that degree with the generation of the toxic gas/ (es) $\quad \mathrm{NO}_{2}, \quad \mathrm{~N}_{2} \mathrm{O}_{4} \quad$ (violent effervescences). For that reason, this step was done in the hood). The above mixture was diluted by using $250 \mathrm{ml}$ warm water. Following this, $30 \%$ $\mathrm{H}_{2} \mathrm{O}_{2}(\sim 30 \mathrm{ml})$ was added till the solution turned bright yellow(to reduce the residual permanganate and manganese dioxide to colorless soluble manganese sulfate). The graphite oxide suspension was washed with $10 \% \mathrm{HCl}$ aqueous solution, then copiously with warm DI water until $\mathrm{pH} \sim 7$, and dried at $40{ }^{\circ} \mathrm{C}$ for 24 hours in oven.( water must be warm to remove mellatic acid which may be found as a side product ) Finally, graphite oxide was dispersed in DI water with GO concentration of 1 $\mathrm{mg}$ per $\mathrm{ml}$ by ultrasonic cleaner. Preparation of TCH [20, 21]:

Hydrazine hydrate $(20 \mathrm{ml})$ was added drop wise to $5 \mathrm{ml}$ carbon disulphide $\left(\mathrm{CS}_{2}\right)$. This mixture was refluxed for 30 minutes, until yellowwhite precipitate was formed. The yellow-white precipitate was washed in ethanol, recrystallized in distill water yet white crystals were formed, dried it in $70^{\circ} \mathrm{C}$ for 4 hours.

\section{Preparation of GO-TCH:}

Graphene oxide (0.5 g) was mixed with $1.0 \mathrm{~g}$ of thiocarbohydrazide (TCH) in $25 \mathrm{ml}$ Pyrex beaker. The mixture was grind and put in a sand bath with a temperature of $160{ }^{\circ} \mathrm{C}$. This mixture was stirred by spatula until it will be melted. The new substance was washed with hot deionized water to remove unreacted $\mathrm{TCH}$ and dried at $70{ }^{\circ} \mathrm{C}$ for 4 hours. Preparation of PAni:

Distillated aniline $(3 \mathrm{ml})$ was placed in an ice bath at $0{ }^{\circ} \mathrm{C}$ for 10 minutes.
Then, $20 \mathrm{ml}$ of $1 \mathrm{M} \mathrm{HCl}$ and $20 \mathrm{ml}$ of (2 g Ammonium persulphate (APS) dissolved in $20 \mathrm{ml} 1 \mathrm{M} \mathrm{HCl}$ ) was added correspondingly, with keeping the temperature at $0{ }^{\circ} \mathrm{C}$. Then the above solution was stirred for 2 hours in an ice bath and the resulting solution was kept in the refrigerator overnight. The yield filtered and washed with distillated water four times and with ammonium hydroxide $1 \mathrm{M}, 20 \mathrm{ml}$ with stirring for 30 minutes. Then filtered and washed with distillated water until the $\mathrm{pH}$ was 6-7.Finally, the precipitate was washed with $15 \mathrm{ml}$ of benzene with stirring for $15 \mathrm{~min}$ and dried at 80 ${ }^{\circ} \mathrm{C}$ for 6 hours.

\section{Preparation of GO-PAni:}

Graphene oxide(1 g) was sonicated with distillated aniline for 20 minutes and filtered. The collected product was placed in a small beaker in an ice bath at $0{ }^{\circ} \mathrm{C} .20 \mathrm{ml}$ of $1 \mathrm{M} \mathrm{HCl}$ was added drop wise and $10 \mathrm{ml}$ of (1 $\mathrm{g}$ of Ammonium persulphate (APS) dissolved in $10 \mathrm{ml}$ of $1 \mathrm{M} \mathrm{HCl}$ ) was added drop wise with keeping the temperature at $0{ }^{\circ} \mathrm{C}$. This solution was stirred for 2 hours in an ice bath, then the solution was kept in the refrigerator overnight. The yield filtered and washed with distillated water four times and with $20 \mathrm{ml}$ ammonium hydroxide $1 \mathrm{M}$ with stirring for 30 minutes, then filtered and washed with distillated water until the $\mathrm{pH}$ was neutral. Finally, the precipitate was washed with benzene and dried at $80{ }^{\circ} \mathrm{C}$ for 6 hours.

Preparation of GO containing benzoimidazol \& benzoxazol[22, 23]: Typically, $1 \mathrm{~g}$ GO was dispersed in $300 \mathrm{ml}$ DI water, $6 \mathrm{~g}$ ophenylenediamine (oPD) was dispersed in $100 \mathrm{ml}$ ethanol by ultrasonicator, Then, the oPD solution was added into the GO suspension, small amount of poly phosphoric acid was added to this mixture. This mixture was ultrasonicated for 1hour. 
The solution was then sealed in a 500 ml Pyrex beaker and stirred for 7 days at room temperature and 5 hours at 180 ${ }^{\circ} \mathrm{C}$. The mixture was naturally cooled to room temperature, filtered, washed for several times by distilled water and dried at $60^{\circ} \mathrm{C}$ for 12 hours in oven.

\section{Instruments:}

The prepared materials are characterized by $\mathrm{X}$-ray diffraction using (Shemadzu- XR - 6000) device with Nickel - Cooper filter for the $\mathrm{X}$ ray radiation $(\mathrm{Cu} \mathrm{K \alpha}, \lambda=1.5406 \AA)$.

The morphology of nano materials were performed using atomic force microscope by PHYWE AFM.

The Fourier transform infrared (FTIR) spectra were recorded at room temperature on 65 FT-IR Perkin Elmer Spectrophotometer orWQF-510 spectrophotometer ranging from 400 to $4000 \mathrm{~cm}^{-1}$.

Sonicator Soniprep 150 was used for dispersing of nano particles in order to make nano materials suspension.
Electronic Test Device was used measure to the Inductance (L), Capacitance (C), and Resistance $(\mathrm{R})$ of a nano materials using HEWLETT.PACKARDLCR.

\section{Results and Discussion: FTIR characterization: \\ FTIR of GO:}

The FTIR spectrum of GO (Figure 2) shows a broad peak at $3406 \mathrm{~cm}^{-1}$ of $\mathrm{OH}$ in the high frequency area. The absorption peaks at $2942 \mathrm{~cm}^{-1}$ and $2845 \mathrm{~cm}^{-1}$ represent the symmetric and anti-symmetric stretching vibrations of $\mathrm{CH}_{2}$. The peak of stretching $\mathrm{C}=\mathrm{O}$ appears at $1718 \mathrm{~cm}^{-1}$. While the peak centered at $1622 \mathrm{~cm}^{-1}$ is assigned to $\mathrm{C}=\mathrm{C}$ bonds associated with skeletal vibrations of unoxidized graphite domains. $1381 \mathrm{~cm}^{-1}$ represented the vibrations $\mathrm{C}-\mathrm{O}$ of carboxylic acid Finally, the absorption peaks at $1200 \mathrm{~cm}^{-1}$ and $1128 \mathrm{~cm}^{-1}$ correspond to the stretching vibrations of $\mathrm{C}-\mathrm{O}$ of epoxy and alkoxy groups [24,25].

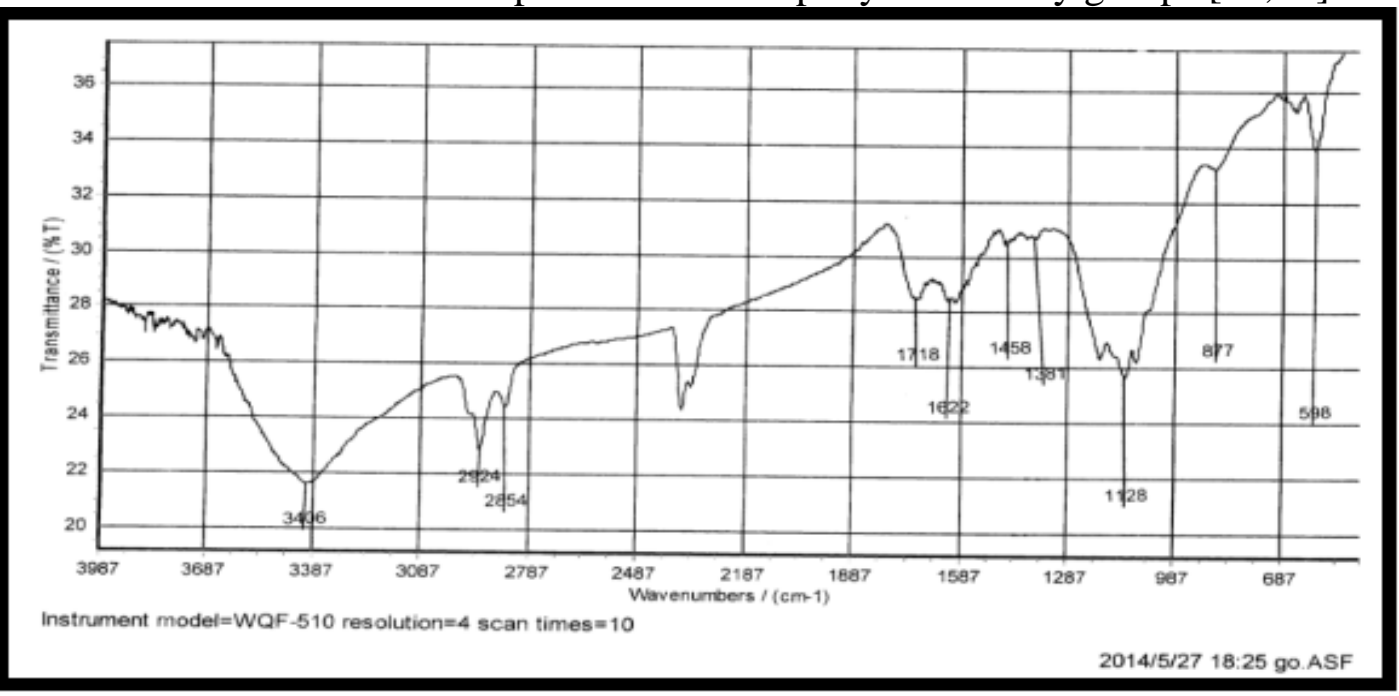

Fig.( 2) FTIRSpectrum of graphene oxide

\section{FTIR of TCH:}

Thiocarbohydrazide spectrum (Figure 3) showed peaks at 1531,755 and $1490 \mathrm{~cm}^{-1}$ which are associated for $\mathrm{N}-\mathrm{H}$ wagging, bending and $\mathrm{C}-\mathrm{N}$ stretching vibration, respectively. The bands of the characteristic $(\mathrm{C}=\mathrm{S})$ stretching were observed in the IR spectrum at 1286 and $933 \mathrm{~cm}^{-1}$. The band in $3305 \mathrm{~cm}^{-1}$ is due to $\mathrm{N}-\mathrm{H}$ stretching vibration, and the bands at 3274 and $3204 \mathrm{~cm}^{-1}$ are due to $\mathrm{NH}_{2}$ stretching vibrations. 1639 and 1142 $\mathrm{cm}^{-1}$ bands are assigned to the $\mathrm{NH}_{2}$ bending and wagging vibrations [26, 27]. 


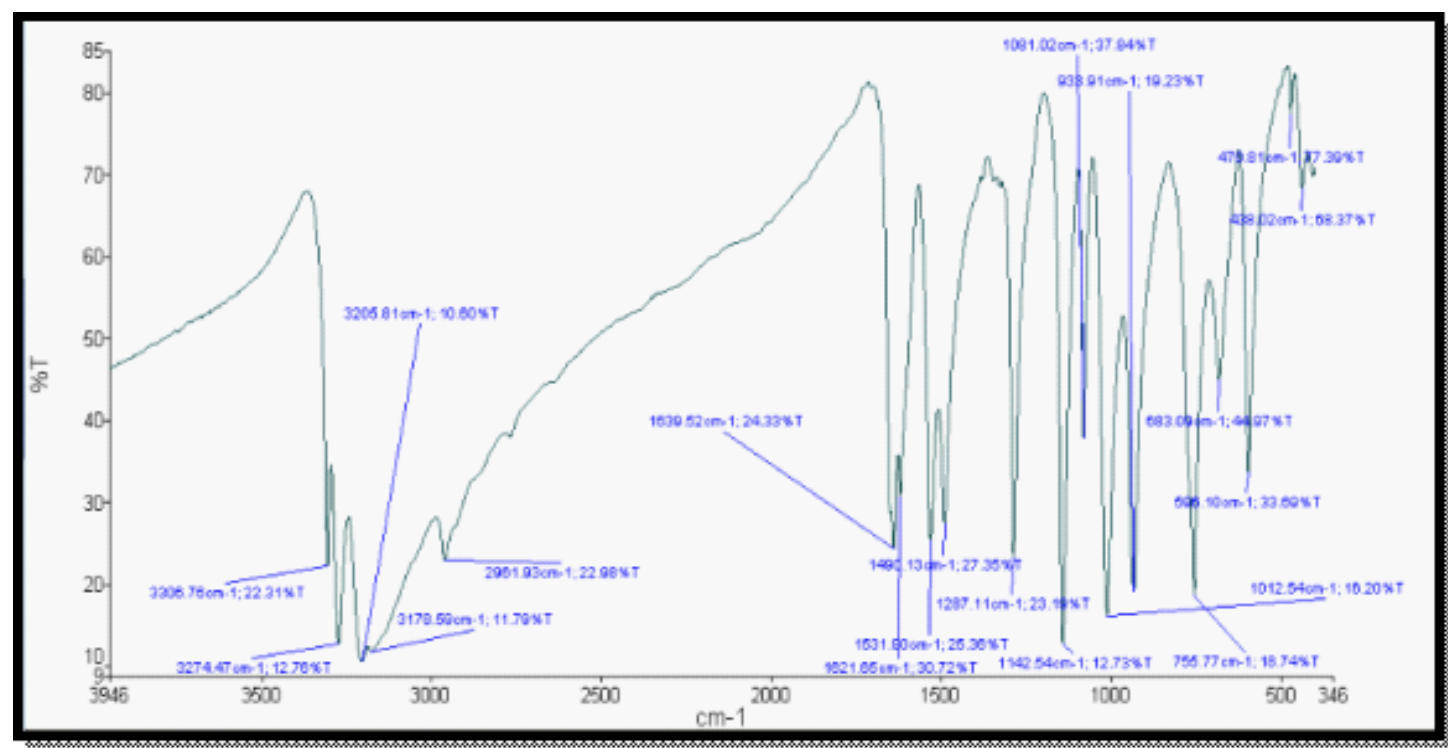

Fig. ( 3) FTIR Spectrum of TCH

\section{FTIR of GO-TCH:}

The infrared Spectrum of this compound shows decreasing the characteristic bands of graphene oxide such as a band 3435, 1261, 1021 and $1722.5 \mathrm{~cm}^{-1}$ which are assigned to the $\mathrm{O}-\mathrm{H}, \mathrm{C}-\mathrm{O}-\mathrm{H}$ (OH bends) C-O-C of epoxy and $\mathrm{C}=\mathrm{O}$ of (residual of carbonyl groups), and shows many new characteristic bands which

attributed to the reaction of graphene oxide with thiocarbohydrazide. These diagnostic bands are; the double band at $2954,2925 \mathrm{~cm}-1$ assigned to $\mathrm{NH} 2$ stretching vibration, $1600 \mathrm{~cm}-1$ and $1378 \mathrm{~cm}-1$ assigned to $\mathrm{NH} 2$ bend and C-N stretching vibration respectively, weak band at $1458 \mathrm{~cm}-1$ assigned to $\mathrm{N}$ $\mathrm{N} \mathrm{cm}-1$ stretching vibration.

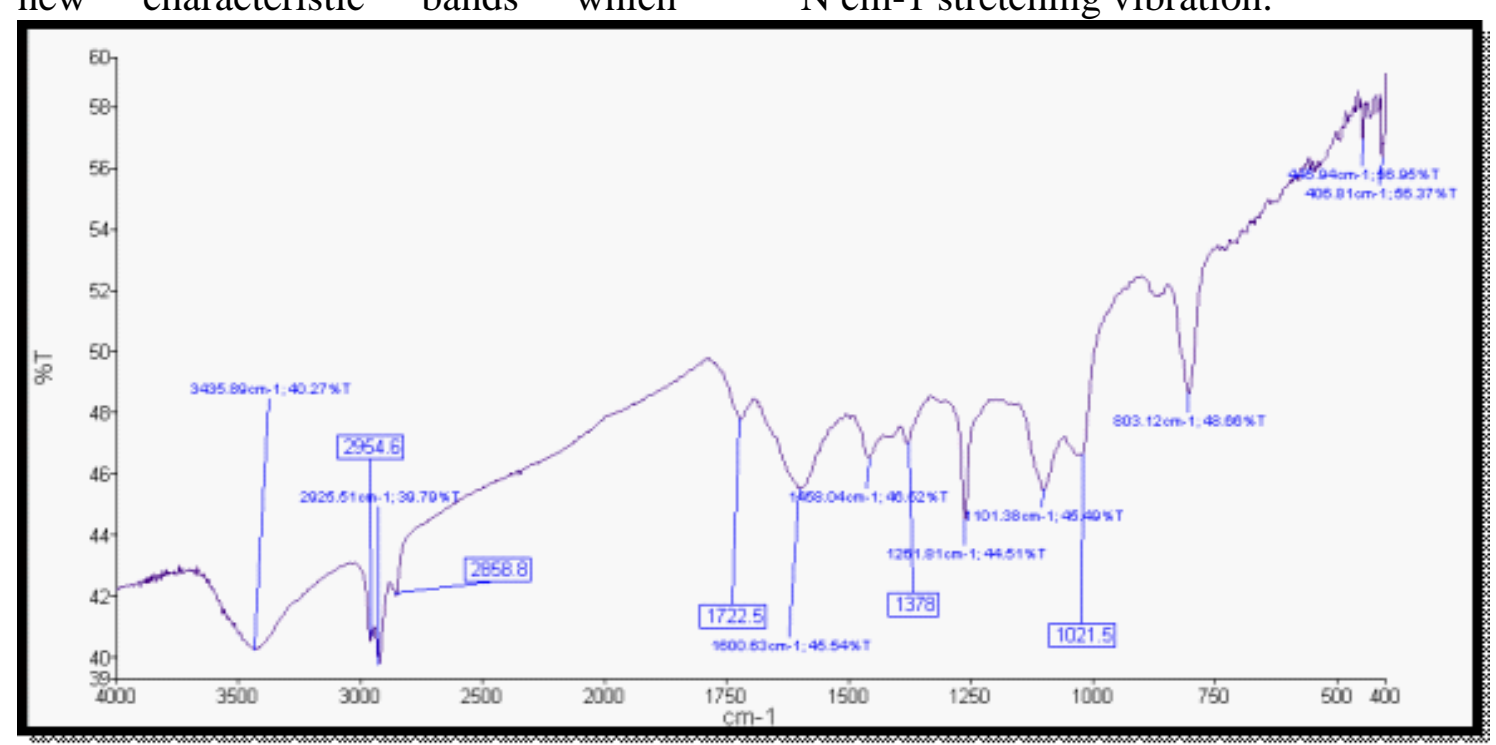

FTIR of PAni:

As in (Figure 5) the peaks at 1586 and $1491 \mathrm{~cm}^{-1}$ corresponding to $\mathrm{C}=\mathrm{C}$ quinonoid and benzenoid deformation vibrations. 1293 and $1143 \mathrm{~cm}^{-1}$ are assigned to the $\mathrm{C}-\mathrm{N}$ of 2aromatic amine stretching deformation and $\mathrm{C}=\mathrm{N}$ stretching of $\quad(-\mathrm{N}=$ quinoid=N-), respectively. While the band at 824 $\mathrm{cm}^{-1}$ is attributed to $\mathrm{C}-\mathrm{H}$ of aromatic ring. The stretching vibration of $\mathrm{N}-\mathrm{H}$ shows a broad peak at $3388 \mathrm{~cm}^{-1}$ [28]. 


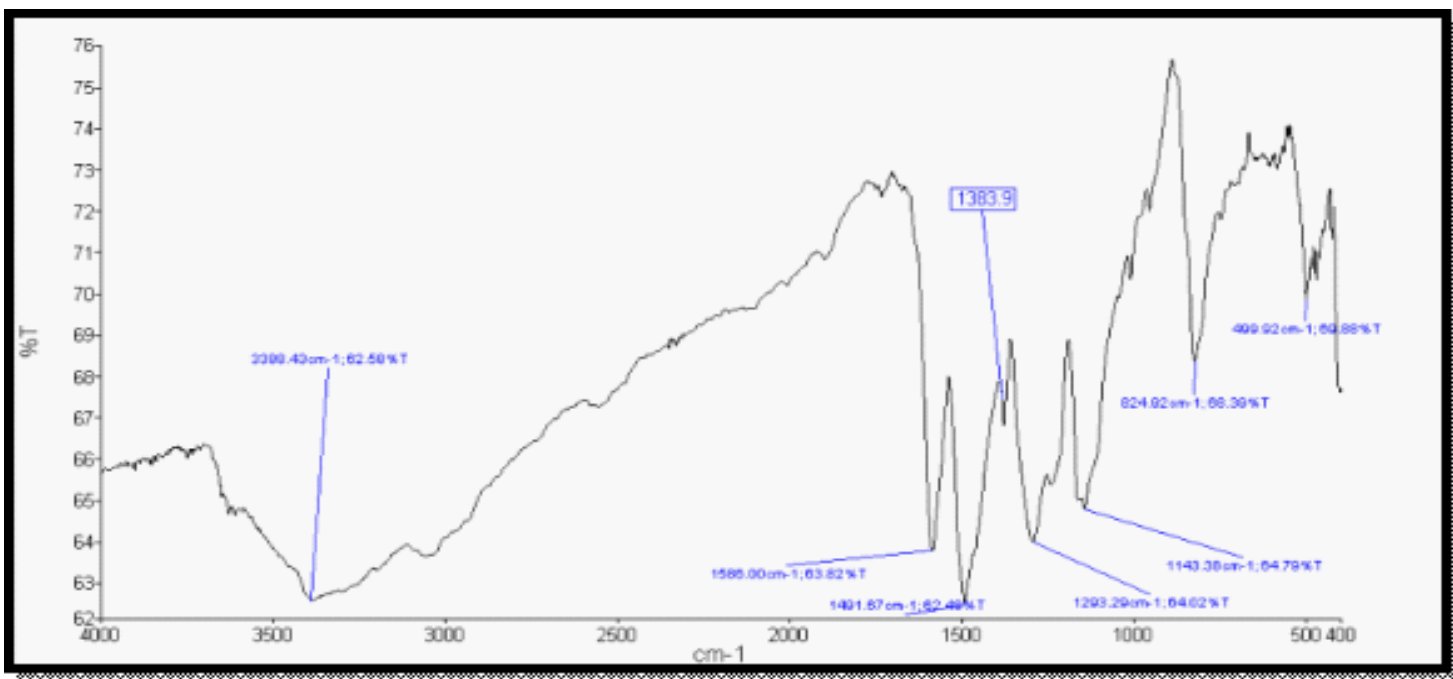

Fig. ( 5) FTIR Spectrum of PAni

\section{FTIR of GO- PAni:}

All character bands of PAni chains are observed in GO- PANI composite but the PAni bands are slightly shifted to lower frequency (Figure 6). This case indicates the p-p stacking and hydrogen bonding between GO nanosheets and the PAni backbone and hydrogen bonding between GO nanosheets and the PAni backbone.

These peaks are 1574 and $1488 \mathrm{~cm}^{-1}$ corresponding to $\mathrm{C}=\mathrm{C}$ quinonoid and benzenoid stretching vibrations. 1297 and $1135 \mathrm{~cm}^{-1}$ are assigned to the C-N of 2aromatic amine stretching deformation and $\mathrm{C}=\mathrm{N}$ stretching of $(-$ $\mathrm{N}=$ quinoid=N-), respectively. $823 \mathrm{~cm}^{-1}$ band is attributed to $\mathrm{C}-\mathrm{H}$ aromatic ring. The stretching vibration of $\mathrm{N}-\mathrm{H}$ shows a broad peak at $3196 \mathrm{~cm}^{-1}$. All these bands clearly indicate the presence and formation of GO-PAni[29].

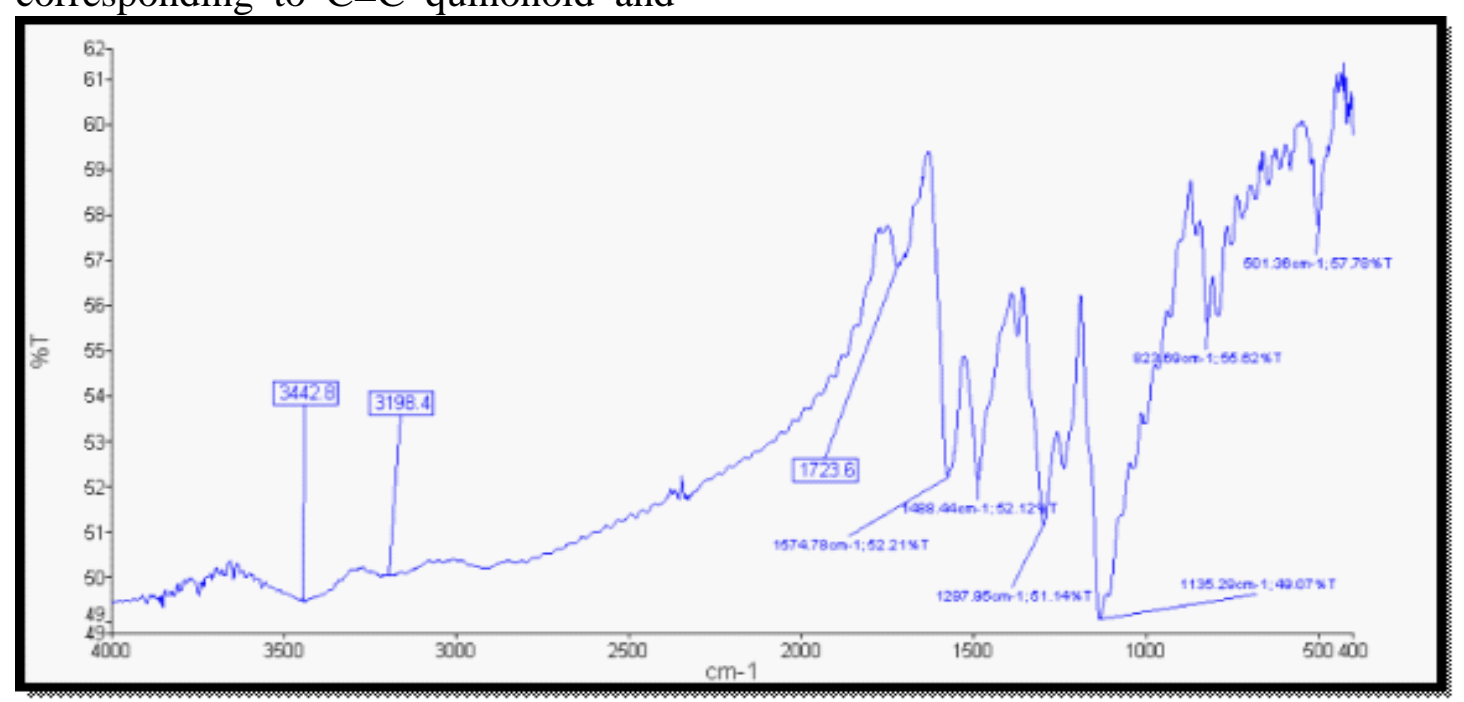

Fig. (6)FTIR Spectrum of GO-PAni

FTIR of GO containing benzoimidazol\& benzoxazol:

The bands at 1707 and $1220 \mathrm{~cm}^{-1}$ disappear(Figure 7), moreover, the new bands at $1574,1544 \mathrm{~cm}^{-1}$ are attributed to the skeletal stretching vibration mode of quinoid and benzoid rings in phenazine. The bands at $1630,1257 \mathrm{~cm}^{-1}$ can be attributed to the stretching of $\mathrm{C}=\mathrm{N}$ and $\mathrm{C}-\mathrm{N}$, respectively the other one at $767 \mathrm{~cm}^{-1}$ in the fingerprint spectrum region also can be assigned to the characteristic bands of phenazine[21]. 


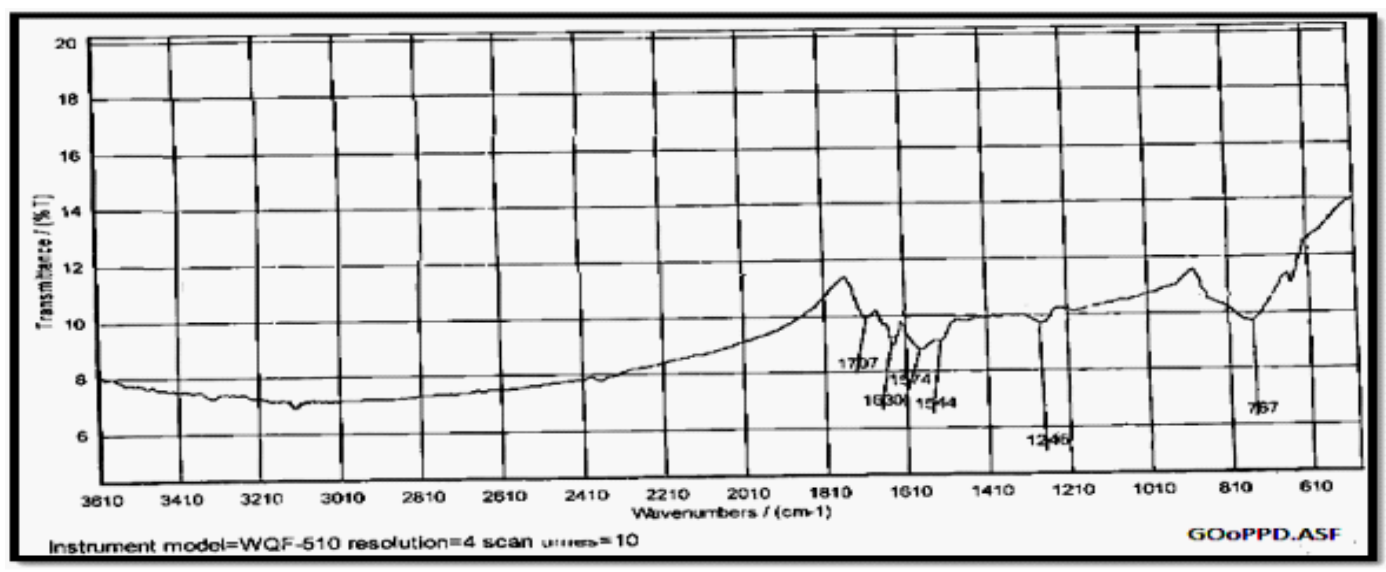

Fig. (7) FTIR Spectrum of graphene oxide containing benzoimidazol \& benzoxazol

\section{X-Ray Diffraction Characterization (XRD): XRD of GO:}

$\mathrm{X}$-ray diffraction pattern (Figure 8) of GO powder shows a large interlayer spacing equal to $8.12 \mathrm{~A}^{\circ}$ at the position $10.8^{\circ} 2 \theta$ and other two bands at $(2 \theta$ $\left.=23.95^{\circ}\right)$ and peak at $\left.\left(2 \theta=43.79^{\circ}\right)\right)$ attributed to the intermediate layer.

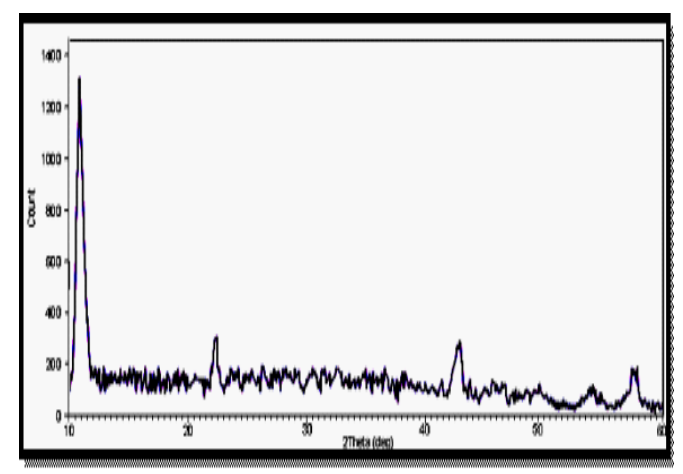

Fig. (8) XRD of graphene oxide

\section{XRD of TCH:}

The $\mathrm{x}$-ray diffraction pattern of thiocarbohydrazide(Figure 9) exhibit major three peaks at 29.5, 15.84 and 72.98 and show an inner layer spacing approximately $3.02,5.58$ and 1.29 , respectively without impurity peaks. This indicates formation of pure $\mathrm{TCH}$.

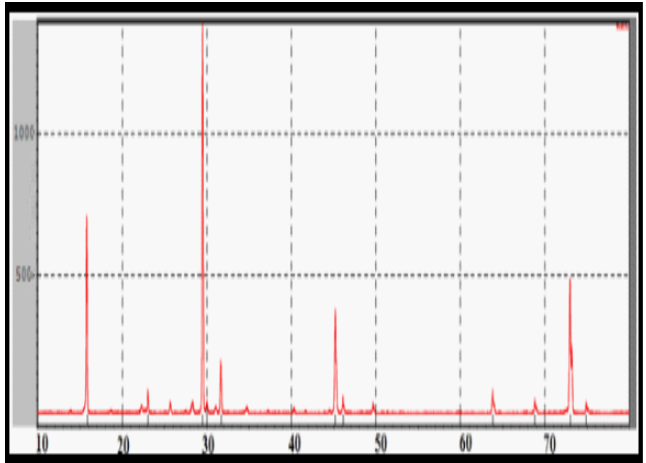

Fig. ( 9) XRD Patterns of TCH

\section{XRD of GO-TCH:}

The XRD pattern (Figure 10) shows new three peaks at $2 q=26.5,25.5$ and 24.7, these bands corresponding to the chemically converted graphene oxide into GO-TCH. Additionally d- spacing has been decreased. When comparing with $\mathrm{GO}$ and $\mathrm{TCH}$, it has been indicated that $\mathrm{TCH}$ has been reacted and grafted in the edges and the surface of GO.

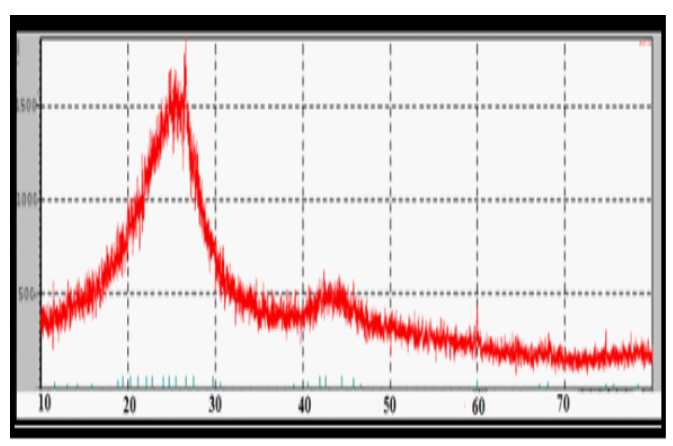

Fig. ( 10) XRD of GO-TCH 


\section{XRD of PAni:}

The X-ray diffraction pattern of PAni powder exhibits a narrow peak than that found in nanoparticles. XRD of pure PAni shown is in (Figure 11). The main peaks appeared at 19.8, 20.9 and $25.2^{\circ} 2 \theta$. The peak centered may be ascribed to the repetition of benzenoid and quinoid rings in PAni chains and the peak at $2 \theta=\sim 25^{\circ}$ may be caused by the periodicity perpendicular to the polymer chain, while the peak at $2 \theta=$ $\sim 20^{\circ}$ also represents the typical distance between the ring planes of benzene rings in nearby chains or the close-contact inter-chain distance [27].

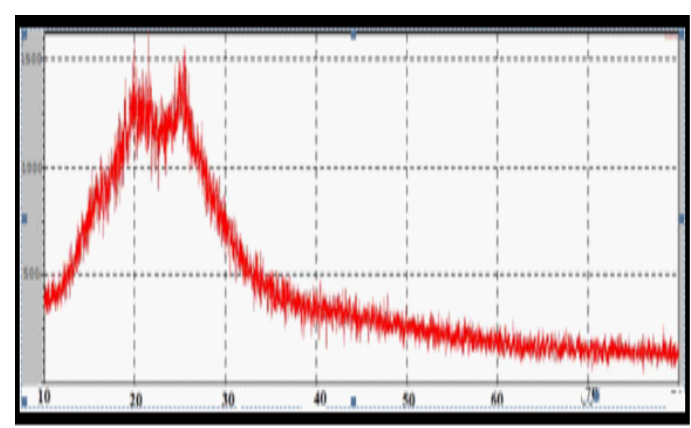

Fig. (11) XRD ofXRD of PAni

\section{XRD of GO-PAni:}

Three new broad peaks of graphene oxide functionalized with poly aniline (Figure 12) are centered at $2 \theta=8.3^{\circ}$ and broad intense peak at $25.6^{\circ}$ and around $43.1^{\circ}$ correspond to (001), (002) and (100). In the GO-functionalized with poly aniline, we observed a weak and broad peak appearing nearly at $2 \theta$ $=8.3$, which is lower than that of graphene oxide. This could imply that the inter planar spacing of the graphene oxide functionalized with poly aniline composite was broadened due to possible intercalation of poly aniline and that the graphene oxide was fully exfoliated by treatment with poly aniline. Therefore, the XRD patterns confirm also the formation of poly aniline grafting on the surfaces of the graphene oxide. These results provide further insight and clear evidence for the formation of functionalized graphene with poly aniline from graphene oxide during the process [30].

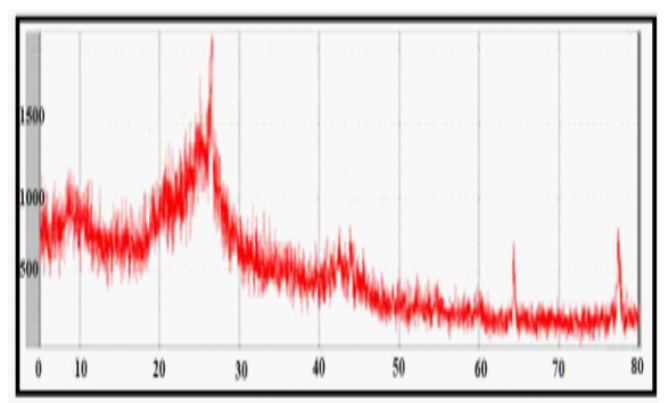

Fig. (12) XRD of GO-PAni

\section{XRD of GO containing \\ benzimidazole \& benzoxazole:}

GO containing benzoimidazol \& benzoxazol (Figure 13) shows a slightly high angle of reflection at $12.4^{\circ}$ with a reduced interlayer distance of 7.16 $\AA$ for GO-benzoimidazol. This decreased of interlayer distance can be explained by the formation of benzoxazole and benzoimidazol rings on the edges of GO after covalent functionalization, because the introduced aromatic molecules will weaken the electrostatic repulsion between the GO sheets and thus induce a smaller interlayer distance. Additionally, bands at $20-25^{\circ}$, corresponding to the chemically converted graphene are observed in GO-benzoimidazol, indicating the partial reduction and re-stacking of GO occurring during the functionalization process [31].

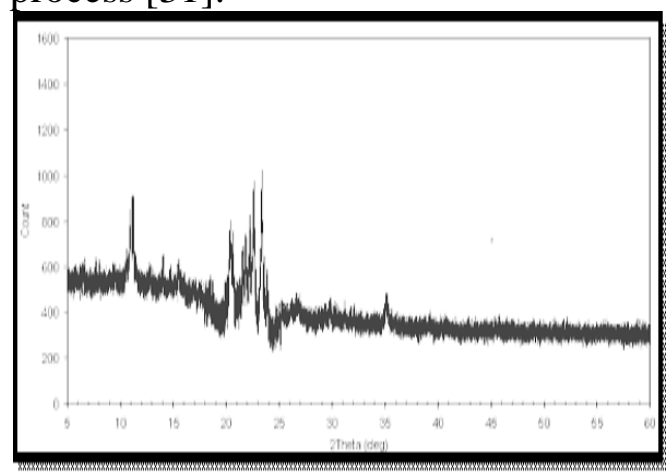

Fig. (13) XRD of GO containing benzoimidazol \& benzoxazol 
Atomic Force Microscope (AFM):-

AFM investigations of pure and functional GO all Figures [14- A, B, C, $\mathrm{D}]$ represented the $\mathrm{GO}$ and $\mathrm{GO}$ with different amine functional groups. AFM measurements showed the GO sheets and GO-TCH with thickness about 4-5 $\mathrm{nm}$.

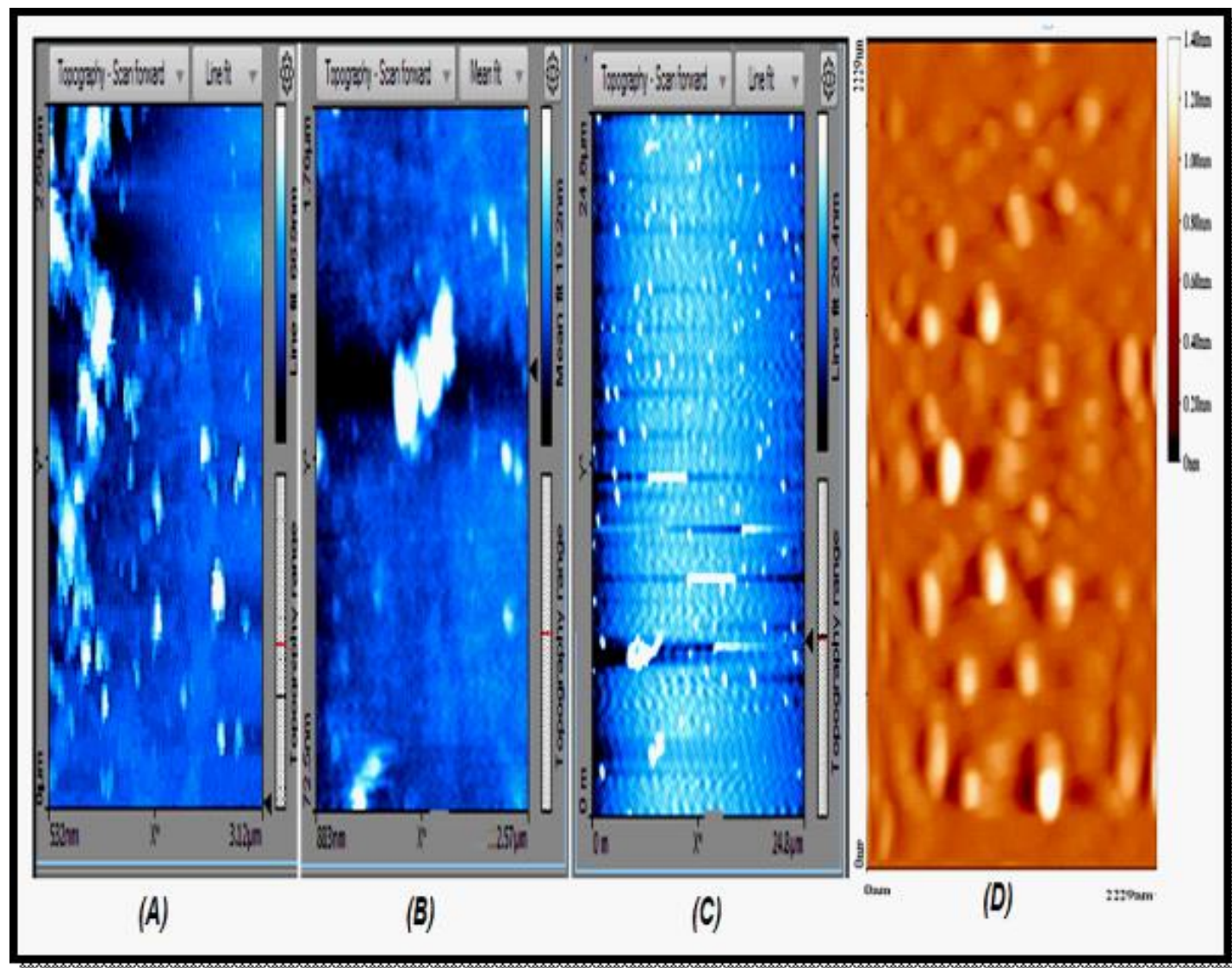

Fig. (14) AFM image of (A) GO, (B) GO-TCH and (C) GO-PAni and (D) GObenzoimadazol and benzoxazol

Electrical nanomaterials:

properties

of

(Figures 15, 16) represented the variation of permittivity with respect to frequency of graphene oxide alone or with functional group. All charts in (Figure15) depicted the variation of the real part of dielectric permittivity $\left(\varepsilon^{\prime}\right)$ with frequency for all types of nanosheet materials.

At low frequencies (400-1000 Hz) permittivity, attained higher values, in all cases, then diminish rapidly with increasing of frequencies (4000$100000 \mathrm{~Hz}$ ).

The charts in (Figures 17) showed the variation of results for the $\mathrm{AC}$ conductivity (AC) nanomaterials at different frequencies. The conductivity depends on frequency, and this was considered as a strong indication for charge migration via the whopping mechanism [32, 33]. Finally, it should be stated that in all studied specimens, conductivity was altered abruptly, implying that the transition from insulating to conductive behavior has been achieved by functionalization of graphene oxide with different amines. The materials that have higher value of $\left(\varepsilon^{\prime}\right)$ and lower value of $\left(\varepsilon^{\prime \prime}\right)$ could be enhanced electrical storage [34]. In this study functional GO with poly aniline possessed a relatively highly $\left(\mathcal{E}^{\prime}\right)$ and $\left(\sigma_{\mathrm{AC}}\right)$ with low $\left(\mathcal{E}^{\prime \prime}\right)$, as shown in (Table 1, 2 and 3). 


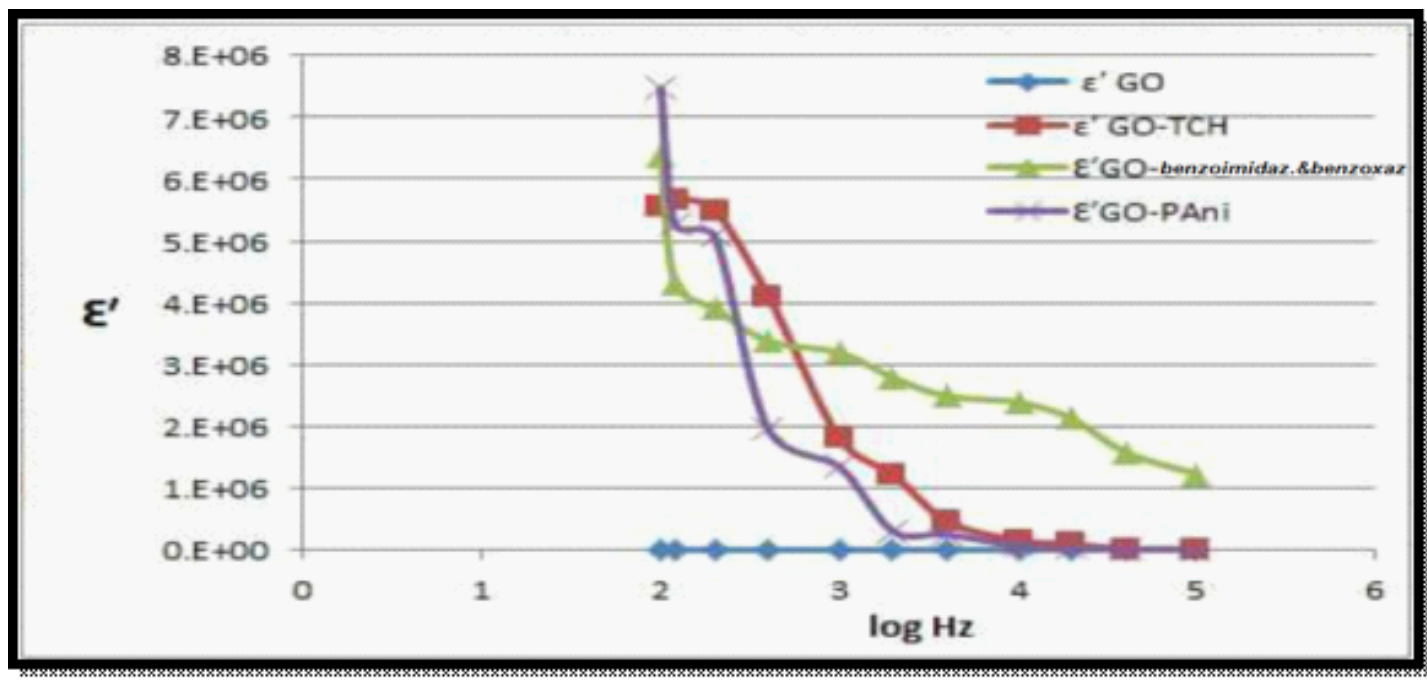

Fig. (15) The relation between the real $\varepsilon$ ' permittivity and frequency values of GO, GO containing benzoimidazol\&benzoxazole, GO-TCH and GO-PAni

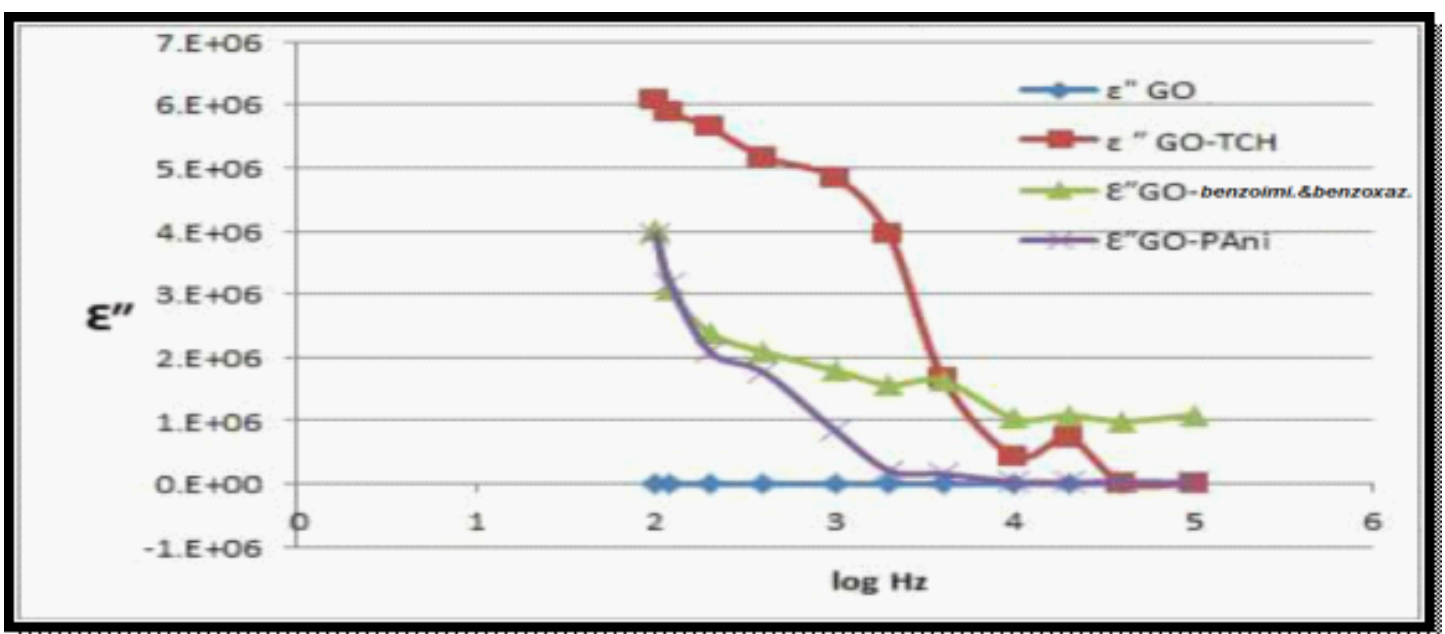

Fig . (16) The relation between the imaginary $\varepsilon^{\prime \prime}$ permittivity and frequency values of GO, GO containing benzoimidazol\&benzoxazole, GO-TCH and GOPAni

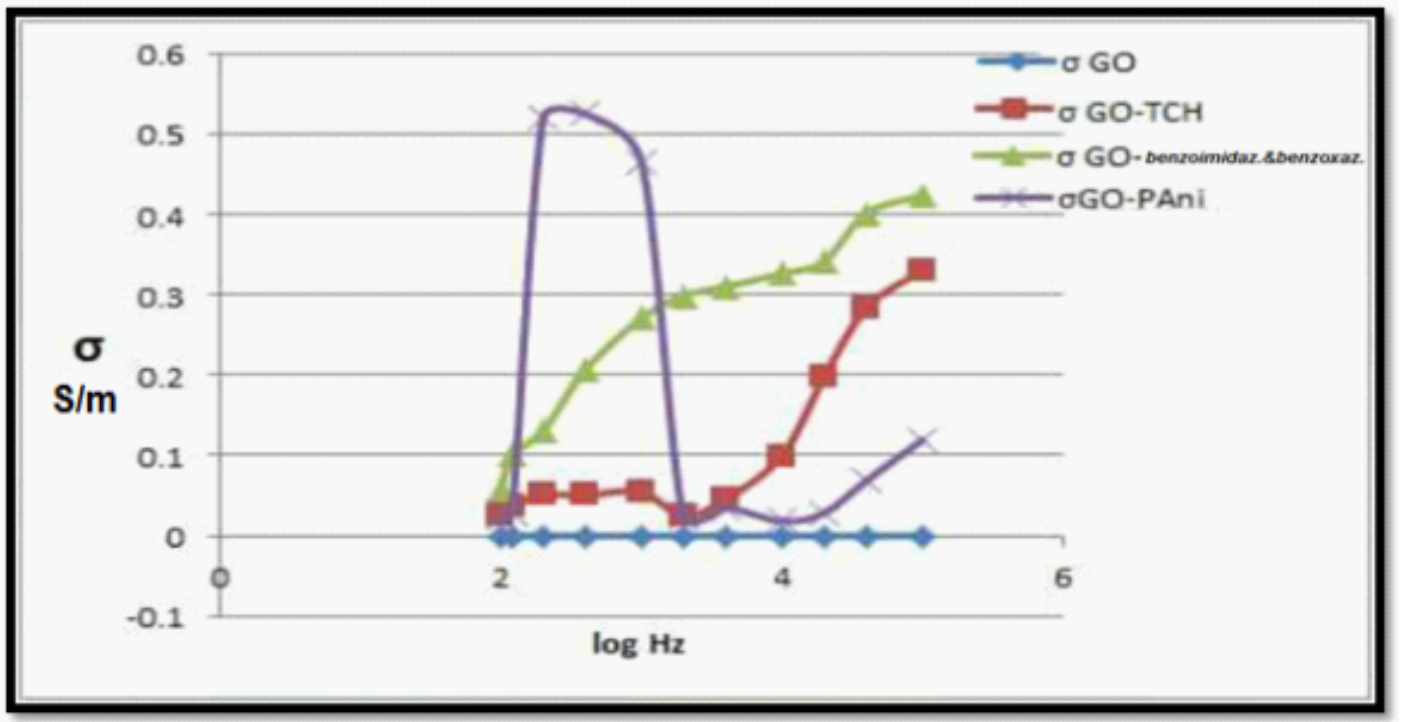

Fig. (17) The relation between conductivity with the frequency change values of GO, GO containing benzoimidazol\&benzoxazole, GO-TCH and GO-PAni 
Table (1)Real permittivityvalues of the prepared nanomaterials

\begin{tabular}{|c|c|c|c|c|}
\hline Log Hz & $\varepsilon^{\prime}$ GO & $\varepsilon^{\prime}$ GO-TCH & $\varepsilon^{\prime}$ GO-benzoimi\&xaz & $\varepsilon^{\prime}$ GO-PAni \\
\hline 2 & 0.31614 & 5559917 & 6375290 & 7472792 \\
\hline 2.079181 & 0.257895 & 5677371 & 4326395 & 5259590 \\
\hline 2.30103 & 0.221053 & 5495094 & 3902617 & 5074041 \\
\hline 2.60206 & 0.177193 & 4109664 & 3379691 & 1956824 \\
\hline 3 & 0.046421 & 1805888 & 3194231 & 1343800 \\
\hline 3.30103 & 0.012789 & 1223075 & 2786302 & 303728.8 \\
\hline 3.60206 & 0.011832 & 463752.6 & 2488948 & 252274.8 \\
\hline 4 & 0.003772 & 155694.3 & 2391159 & 64371.1 \\
\hline 4.30103 & 0.0022 & 97246.51 & 2125087 & 28224.8 \\
\hline 4.60206 & 0.005453 & 16551.89 & 1577956 & 18711.86 \\
\hline 5 & 0.000191 & 5911.389 & 1229061 & 10148.08 \\
\hline
\end{tabular}

Table (2) Imaginary permittivityvalues of the prepared nanomaterials

\begin{tabular}{|c|c|c|c|c|}
\hline $\log \mathrm{Hz}$ & $\varepsilon^{\prime \prime} \mathrm{GO}$ & $\varepsilon^{\prime \prime} \mathrm{GO}-\mathrm{TCH}$ & $\begin{array}{c}\varepsilon^{\prime \prime} \mathrm{GO}- \\
\text { benzoimi\&xaz }\end{array}$ & $\varepsilon^{\prime \prime} \mathrm{GO}-\mathrm{PAni}$ \\
\hline 2 & 0.005348 & 6062937 & 4017597 & 3936252 \\
\hline 2.079181 & 0.005039 & 5878433 & 3084065 & 3177567 \\
\hline 2.30103 & 0.004472 & 5635941 & 2384292 & 2089677 \\
\hline 2.60206 & 0.003653 & 5168165 & 2087145 & 1761040 \\
\hline 3 & 0.000969 & 4846934 & 1792676 & 840522 \\
\hline 3.30103 & 0.00023 & 3937283 & 1566801 & 209937 \\
\hline 3.60206 & 0.000183 & 1658952 & 1631366 & 156078.3 \\
\hline 4 & $4.56 \mathrm{E}-05$ & 439785.7 & 1033718 & 32274.42 \\
\hline 4.30103 & $6.02 \mathrm{E}-05$ & 716978 & 1082161 & 25437.43 \\
\hline 4.60206 & 0.000223 & 16751.87 & 988877 & 30889.4 \\
\hline 5 & $1.66 \mathrm{E}-05$ & 2994.884 & 1089375 & 21506.56 \\
\hline
\end{tabular}

Table (3) conductivityvalues of the prepared nanomaterials

\begin{tabular}{|c|c|c|c|c|}
\hline $\log \mathrm{Hz}$ & $\sigma \mathrm{GO}$ & $\sigma \mathrm{GO}-\mathrm{TCH}$ & $\begin{array}{c}\sigma \mathrm{GO}- \\
\text { benzoimi\&xaz }\end{array}$ & $\sigma$ GO-PAni \\
\hline 2 & $1.05 \mathrm{E}-09$ & 0.026406 & 0.05767 & 0.021877 \\
\hline 2.079181 & $1.39 \mathrm{E}-09$ & 0.037251 & 0.10043 & 0.027862 \\
\hline 2.30103 & $2.11 \mathrm{E}-09$ & 0.050725 & 0.13083 & 0.521274 \\
\hline 2.60206 & $3.49 \mathrm{E}-09$ & 0.05047 & 0.207149 & 0.52615 \\
\hline 3 & $2.33 \mathrm{E}-09$ & 0.054745 & 0.271243 & 0.467162 \\
\hline 3.30103 & $9.72 \mathrm{E}-10$ & 0.023954 & 0.299651 & 0.023336 \\
\hline 3.60206 & $1.25 \mathrm{E}-09$ & 0.045949 & 0.311097 & 0.034698 \\
\hline 4 & $2.71 \mathrm{E}-10$ & 0.099275 & 0.327106 & 0.017937 \\
\hline 4.30103 & $3.31 \mathrm{E}-09$ & 0.19819 & 0.342255 & 0.028275 \\
\hline 4.60206 & $2.06 \mathrm{E}-08$ & 0.28443 & 0.402359 & 0.068671 \\
\hline 5 & $5.2 \mathrm{E}-09$ & 0.331777 & 0.424926 & 0.119529 \\
\hline
\end{tabular}

\section{Conclusions:}

From the electrical measurements, we noticed that the electrical properties of functional GO have been developed.
This promotion in the electrical properties could be attributed to the: (i) The grafting of polyaniline, benzoimidazol \& benzoxazol and TCH 
on the surface and edge of GO leading to fully exfoliated graphene oxide in addition to the chemically reduction of GO that occurred during the functionalization process which that means that these amines behave as reducing agent and converted it to graphene which has a very high conductivity. (ii) The addition of amines promote the electrical properties of GO by increasing the pi system.

Depending on all the above measurements, we can conclude the following series of the electrical properties:

GO-PAni < GO-benzoimidazol \& benzoxazol $<$ GO-TCH $<$ GO
From the previous measurements (FTIR, XRD and AFM) the appropriate structure of graphene oxide functionalized with poly aniline has different bonds that; covalent and noncovalent bonds as in (Figure 18). While in the case of other material, TCH and $\mathrm{o}-\mathrm{PD}$ entered ring close reaction. A reaction of only one GO alcoholic or carboxylic group with amines group makes o-PD and TCH converted into benzoimidazole and tryazole consequently, but the reaction of two neighboring alcoholic groups will convert into benzoxazol. These two compounds may be containing hydrogen bonding with GO sheet.

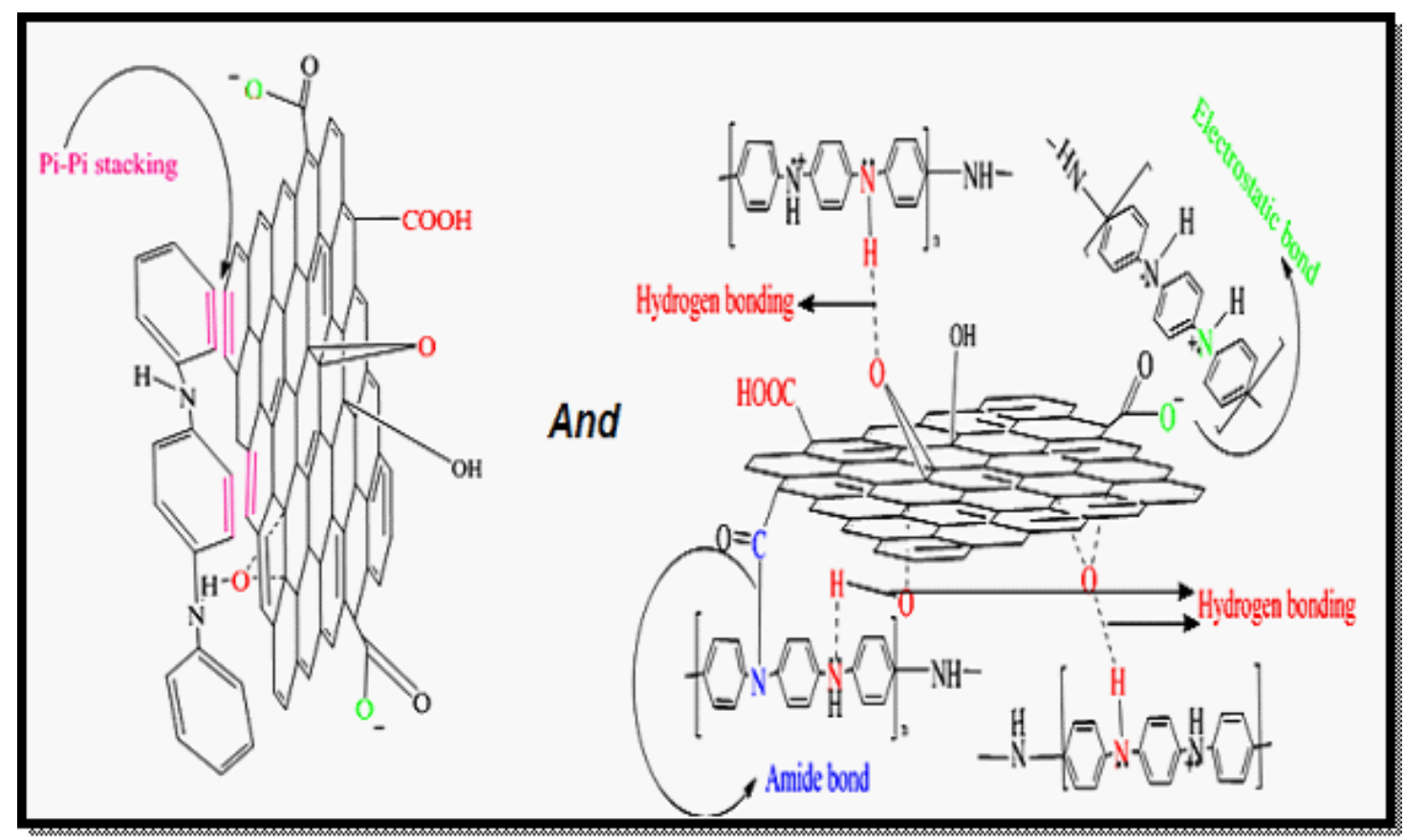

Fig. (18) GO-PAni structure 


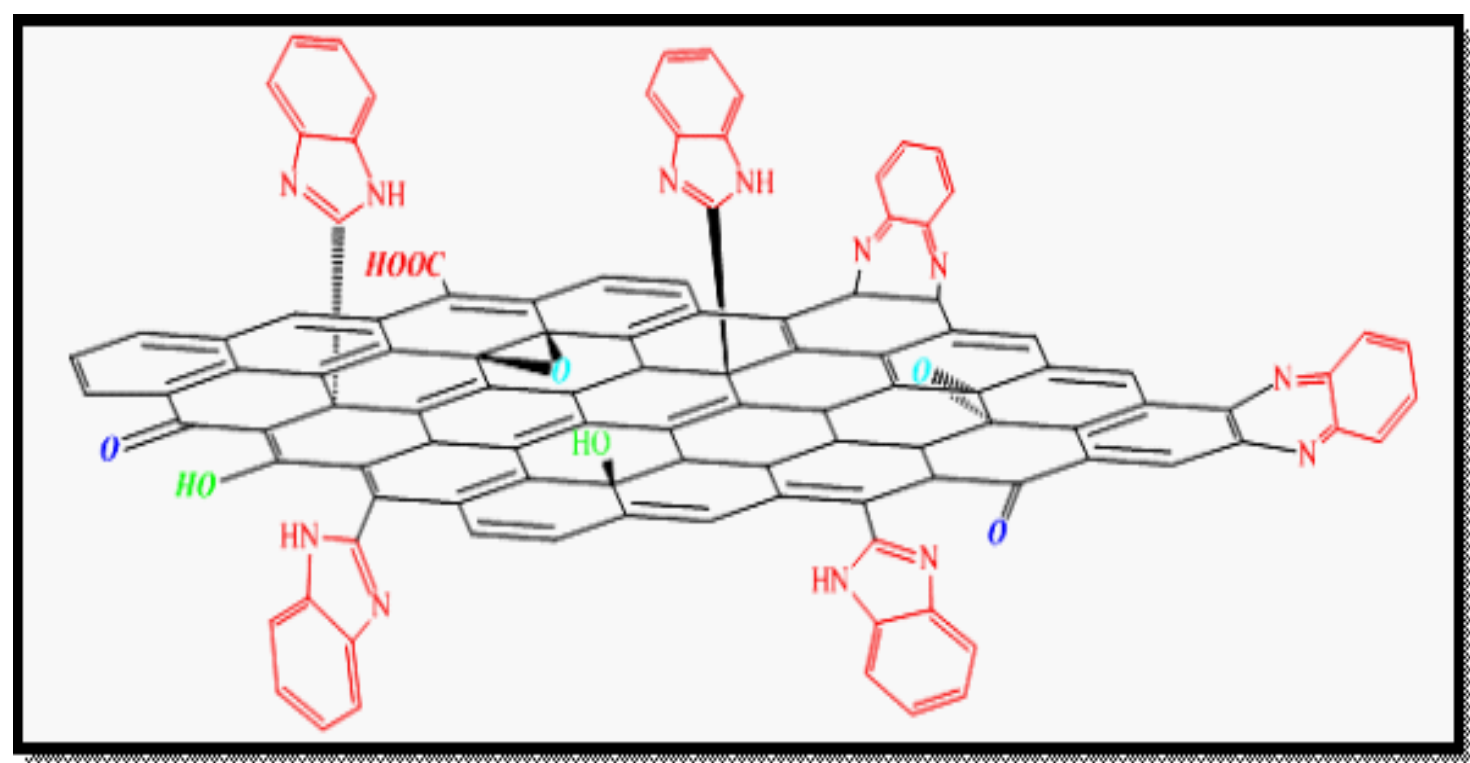

Fig. (19) GO-benzoimidazol\&benzoxazole structure

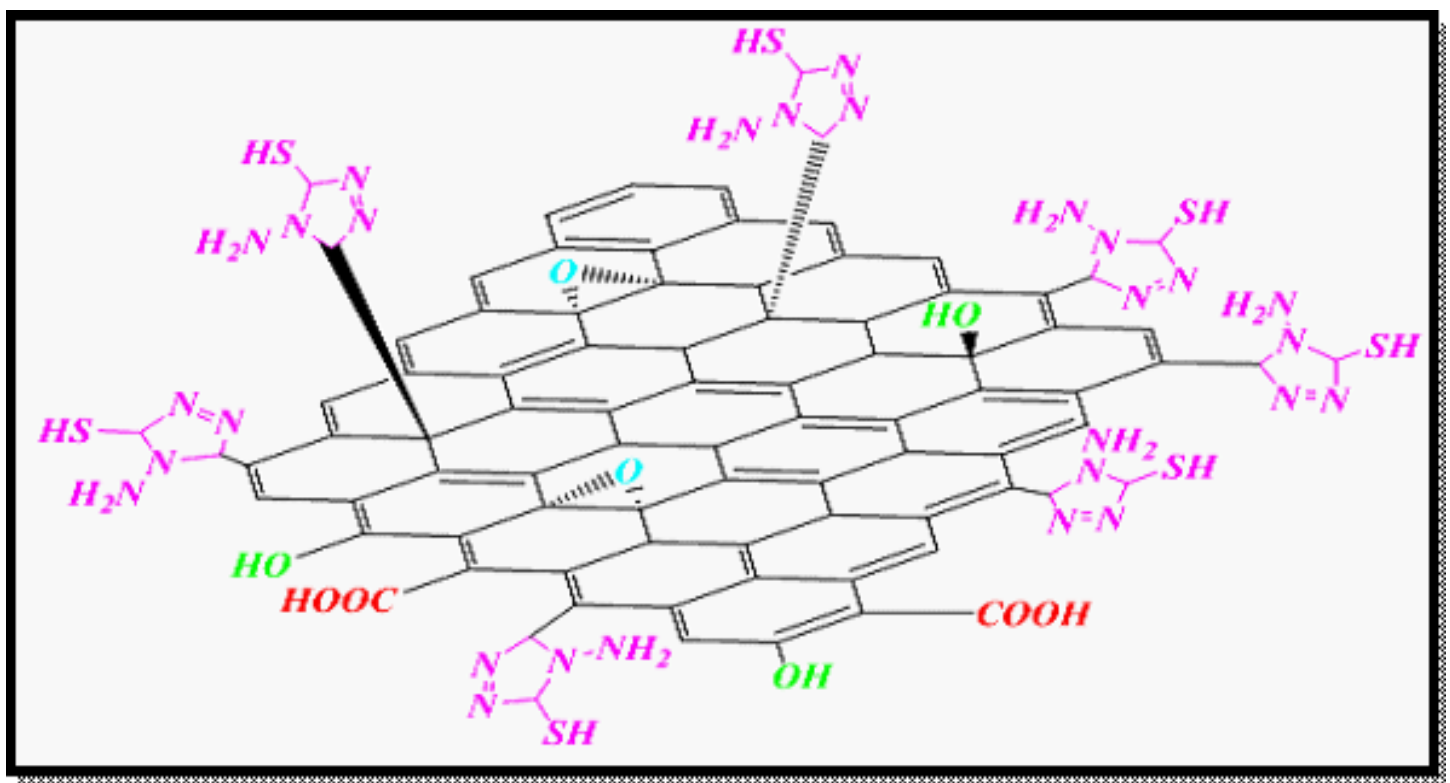

Fig.( 20) GO-TCH structure

\section{References:}

[1] Ying, C; Bingqiao, X; Yingtao, R; Mengying, Y., Yang, Q., Ting, X., Yong, Z.and Yucheng, Wu. 2014. Designed nitrogen doping of fewlayer graphene functionalized by selective oxygenic groups, Nanoscale Research Letters, 9: 646.

[2] Jijun, Z; Lizhao, L; and Fen, L. 2015. Graphene Oxide: Physics and Applications,Springer,DOI 10.1007/978-3-662-44829-8.

[3] Zabihinpour, M; and Ghenaatian, 2013. A novel multilayered architecture of graphene oxide nanosheets for high supercapacitive performance electrode material, H.R.: Synth. Met. 175, 62-67.

[4] Mahboobeh, H; Elaheh, K; G;and Abbas, Y. 2014. Electrical conductivity, thermal conductivity, and rheological properties of graphene oxide-based nanofluids, J Nanopart Res, 16:2788, DOI 10.1007/s11051-014-2788-1.

[5] Lerf, A., He, H; and Klinowski, F;J. 1998. Structure of Graphite Oxide, Chem Phys Lett, 53, 287. 
[6] Lerf , A; He, H; and Klinowski, F;J. ,1998. Structure of Graphite Oxide Revisited ${ }^{\mathrm{II}}$, J .Phys.Chem B, 102:4477.

[7] Owen, C;C; Steven, C;W; Karl, $\mathrm{P} ; \mathrm{W}$; Catherine, B; Markus, B;J; and SonBinh, N;T. 2012. Tuning the Mechanical Properties of Graphene Oxide Paper and Its Associated Polymer Nanocomposites by Controlling Cooperative Intersheet Hydrogen Bonding, ACS nano, 6 , 3, 20082019.

[8] Nanjundan, A; K; Hyun, J;C; Yeon, R;S; Dong, W;C; Liming, D; and Jong, B;B. 2012. PolyanilineGrafted Reduced Graphene Oxide for Efficient Electrochemical Supercapacitors, ACS Nano 6, 2, 1715-1723.

[9] Wei,G; 2015. Graphene Oxide :Reduction Recipes, Spectroscopy, and Applications,Springer ,DOI 10.1007/978-3-319-15500-5.

[10] Liu, Z; Xu, Y; Zhang, X; Zhang, X; Chen, Y;S; and Tian, J. 2009. Porphyrin and fullerene covalently functionalized graphene hybrid materials with large nonlinear optical properties, J Phys Chem B 113:9681- 6.

[11] Xu, Y; Liu, Z; Zhang, X; Wang, Y; Tian, J; Huang, Y; Ma, Y; and Chen, Y; 2009. A Graphene Hybrid Material Covalently Functionalized with Porphyrin: Synthesis and Optical Limiting Property, A.Adv ,Mater 2 ,1,12751279.

[12] Zhang, Y; Hu, W; Li, B; Peng, C; Fan, C; and Huang, Q. 2011. Synthesis of polymer-protected graphene by solvent-assisted thermal reduction process. Nanotechnology, 34, 26-22.

[13] Jie, H; Shunmin, D; Weiming, $\mathrm{X}$; Yadan, P; Shengjun, D; and Ning Z. 2015 . Catalytic behavior of metal-organic frameworks in the
Knoevenagel condensation reaction, Catal Lett, DOI 10.1007/s10562014-1461-8.

[14] Cote, L; Kim, F; Huang, J. $2008 . \quad$ Langmuir-Blodgett Assembly of Graphite Oxide Single Layers, J Am Chem Soc 131, 1043 1049.

[15] Mejias C; Mangadlao, J; Nguyen, H; Advincula, R; and Rodrigues, D. 2014. Graphene oxide functionalized with ethylenediamine triacetic acid for heavy metal adsorption and antimicrobial applications, Carbon 77,289-301.

[16] Akhavan, O; Ghaderi, E.2010 Toxicity of Graphene and Graphene Oxide Nanowalls Against Bacteria, ACS Nano 4,5731-5736.

[17] Balasubramaniyan, R; and Jin, C.2014. Reduced chemically modified graphene oxide for supercapacitor electrode, Nanoscale Research Letters 9: 535 , 2-10.

[18] Wan, Y; Tang, L; Gong, L; Yan, D;Li, Y; Wu, L; Jiang, J; and Lai, G.2014 Toward effective and tunable interphases in graphene oxide/epoxy composites by grafting different chain lengths of polyetheramine onto graphene oxide ,Carbon 69, 467-480.

[19] Hummers, W; S; and Offeman, R; E. 1958, Preparation of Graphitic Oxide J. Am. Chem. Soc 80, 1339.

[20] Hakimi, M; and Alimard, P. 2012 , Graphene: Synthesis and Applications in Biotechnology Review, World Applied Programming, 2 , 6: 377-388

[21] Aly , A; A; Brown, A;B; ElEmary, T; I; Ewas, A;M; and Ramadane. 2009. Hydrazine carbothioamide group in the synthesis of heterocycles, M.ARKIVOC, 150-197.

[22] Yanhong, Z;F;L; Tengfei, Z; KaiL,Z., Long,Xi; M; Yanfeng ,Yi; $\mathrm{ZH}$; Mingjie, and Yongsheng, C; 
2013. Synthesis and supercapacitor performance studies of $\mathrm{N}$-doped graphene materials using ophenylenediamine as the double-N precursor, CARBON 63, 508-516.

[23] WeiA ,L; Ju-Qing, D ; ZhuZhu,L; Xiao-Xu, S; Jing-Zhi,Y; Ming-Dong, L; Z; Jian-Jun, L; Ting ,Y; and Wei, H. 2013, One-pot, aqueous-phase synthesis of graphene oxide functionalized with heterocyclic groups to give increased solubility in organic solvents, RSC Adv., 3,45-49.

[24] Singh,V; Joung, D; Zhai, L; Das, S;S;I;and Seal, S; 2011. Graphene based materials: Past, present and future, Progress in Materials Science 56, 1178-1271.

[25] Metwally, M; A; Khalifa, M; E; and Koketsu, M. 2012. Thiocarbohydrazides: Synthesis and Reactions, American J.of Chem., 2,2: 38-51.

[26] Xiao,T;D; Strutt, P;R; Benaisd, M; Chen, H; and Keart, B;H.1998 Synthesis of high active-site density nanofibrous $\mathrm{MnO}_{2}$-base materials with enhanced permeabilities , Nanostructured Material J., 10,6: 1051-1061.

[27] Wu, X; and Xu, A; 2014. Carbonaceous hydrogels and aerogels for supercapacitors, J. Mater. Chem. A, 2, 4852-4864

[28] Ahmad, A; Esah, H; Zaharah, I; and Shahrir, H.2012. Synthesis of
Uniform Polyaniline Nanofibers through Interfacial Polymerization, Materials, 5, 1487-1494.

[29] 29-Ropert, M; and Silver, S. 1962. Spectroscopic Identification in Organic Compounds,

[30] Chen, W; and Yan, L.2010. Preparation of graphene by a lowtemperature thermal reduction at atmosphere pressure, Nanoscale, 2, 559-563.

[31] Wei,L; Ju-Qing,D; Zhu-Zhu,L; Xiao-Xu,S; Jing-Zhi,Y; Ming-Dong ,X; Ling-Hai,Z; Jian-Jun,L; HaiFeng, Ting; Y; and Wei, H.2013 . One-pot, aqueous-phase synthesis of graphene oxide functionalized with heterocyclic groups to give increased solubility in organic solvents, RSC Adv, 3, 45-49.

[32] Mikhailov, O. 2004. Template synthesis in the M(II)thiocarbohydrazide-diacetyl triple system, Transition Metal Chemistry, $29,732-736$.

[33] Kondawar, S; B; Deshpande, M; D; and Agrawal, S; P. 2012. Resin Composites Reinforced by Nanoscaled Fibers or Tubes for Dental Regeneration, J. of Composite Materials, 2,3: pp 33-36.

[34] Kurzer, F; and wilkinson, $M$. 1966. The chemistry of thiocarbohydrazide, Chem. Abstr, 65,9783 . 


\title{
إضافة بعض الأمينات الأولية والثانوية لأوكسيد الجرافين ودراسة تأثيرها على زئل زيادة خصائصه الكهربائية لاوكيد الجية
}

مصطقى عبد الغقور اللهيتي

\author{
عبدالوهاب حميد الاغا
}

أحمد نجم عبد

قسم الكيمياء ,كلية العلوم ,جامعة ديالى.

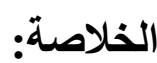

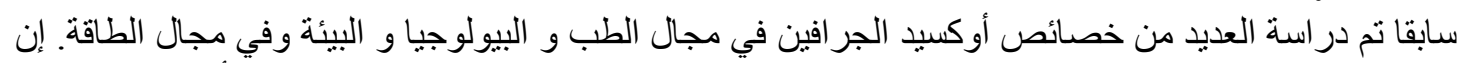

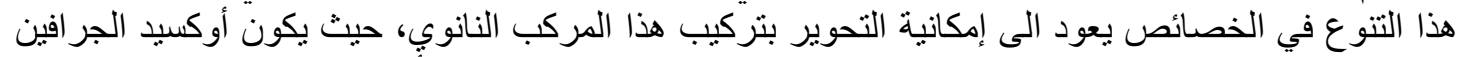

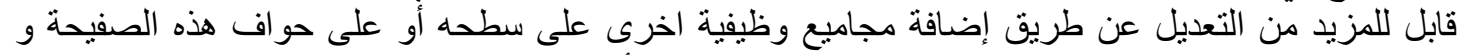

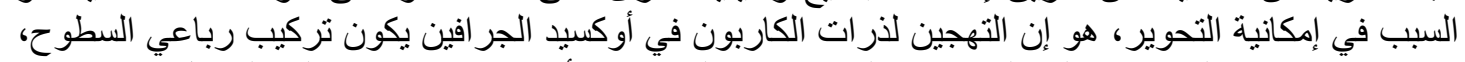

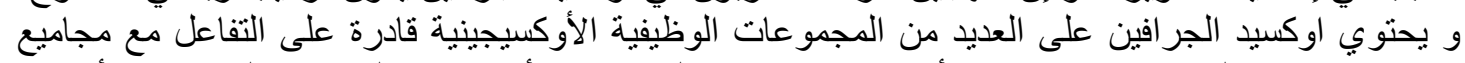

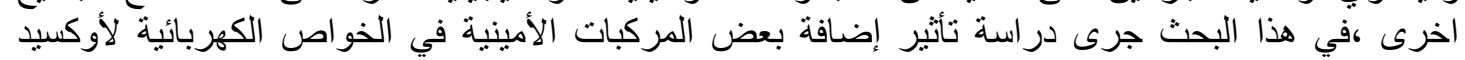

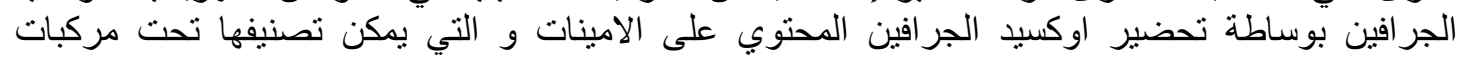

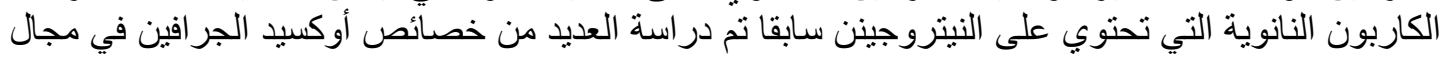

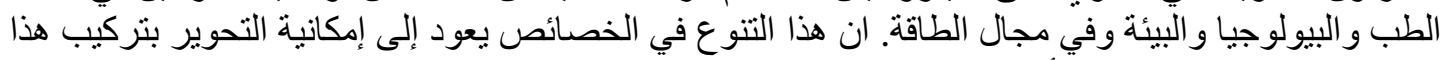

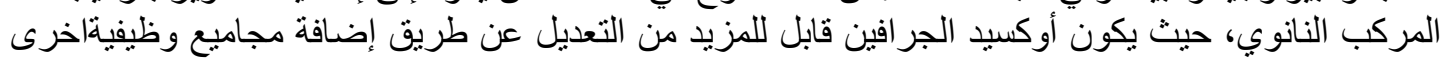

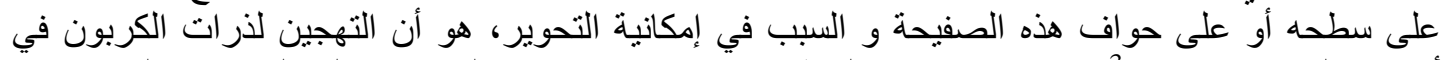

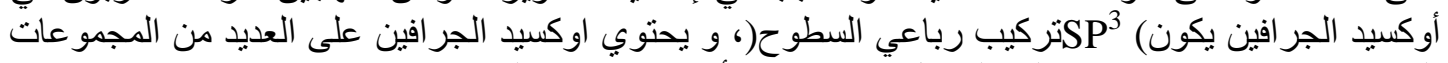

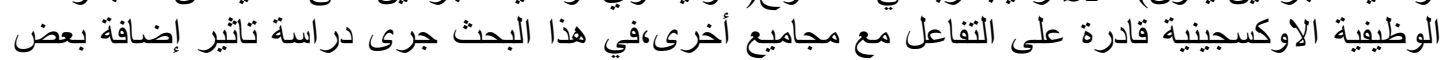

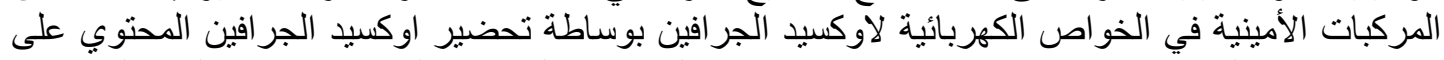

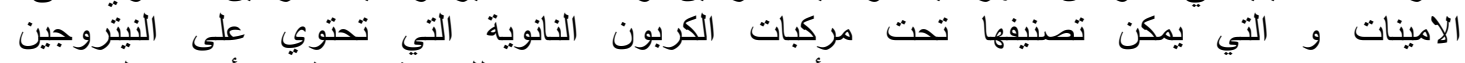

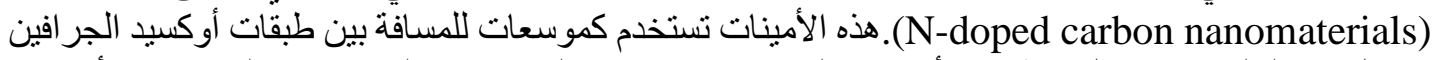

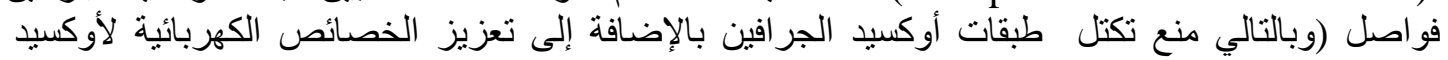

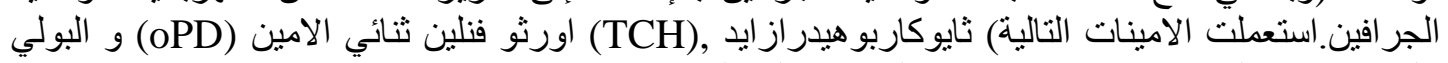

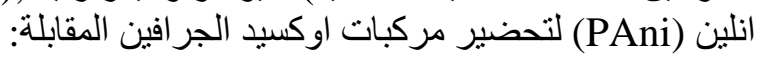

GO-TCH, GO-containing Benzoimadazole\& benzoxazole, and GO-PAni)

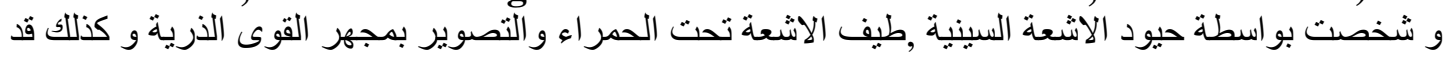

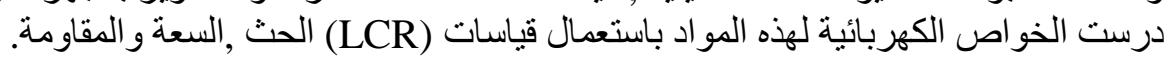
الكلمات المفتاحية:الخصائص الكهربائية، الأمينات الأولية و الثانوية ، أوكسيد الكر افين 